REVISTA DE DERECHO UNED, NÚM. 14, 2014

\title{
REVISIÓN JURISPRUDENCIAL DE LA GUARDA Y CUSTODIA COMPARTIDA E INTERÉS DEL MENOR: NOVEDADES EN TORNO A LA FUTURA LEY DE CORRESPONSABILIDAD PARENTAL
}

\begin{abstract}
JURISPRUDE REVISION OF THE CUSTODY AND THE INTEREST OF THE CHILD: THE FUTURE LAW OF PARENTAL
\end{abstract} CO-RESPONSABILITY

\section{Agustina Herranz GonZÁLEZ}

Abogada. Profesora Tutora. Doctoranda del Departamento de Derecho civil de la UNED ${ }^{1}$

Sumario: I. APUNTES PREVIOS: LA RELEVANCIA DE LOS PRONUNCIAMIENTOS SOBRE GUARDA Y CUSTODIA. II. NORMATIVA VIGENTE. 1. Orden de protección. 2. Guarda y custodia consensuada. 3. Guarda y custodia judicialmente determinada. III. CRITERIOS ACTUALES Y JURISPRUDENCIA RELACIONADA CON LA ATRIBUCIÓN DE LA GUARDA Y CUSTODIA. 1. Supuestos en los que resulta posible su adopción. 2. Aspectos concretos ya resueltos por el Tribunal Supremo. A) Excepcionalidad. B) Relación entre los progenitores. C) Régimen normal y deseable. D) Imprescindible petición de parte. E) No basta una motivación puramente retórica. F) No accede a la casación la valoración de las circunstancias concretas. G) Determinar el domicilio del menor es una facultad inherente a la patria potestad. H) Posibilidad de modificar anteriores medidas con fundamento

${ }^{1}$ Agradezco al Departamento de Derecho civil de la UNED, el apoyo que me han dispensado y en particular a mis directoras de tesis por las revisiones sucesivas de mis trabajos y artículos, Profesora M. ${ }^{a}$ Fernanda Moretón Sanz y M. ${ }^{a}$ Paz Pous de la Flor. 
en las nuevas tendencias. IV. ANTEPROYECTO DE LEY SOBRE EL EJERCICIO DE LA CORRESPONSABILIDAD PARENTAL. V. CONCLUSIONES. VI. BIBLIOGRAFÍA. VII. ÍNDICE DE RESOLUCIONES CITADAS

Resumen: La seguridad jurídica en materia de guarda y custodia aconsejan establecer criterios comunes de actuación. El objetivo es la tutela del supremo interés del menor, principio rector en esta materia. La STS 29 abril 2013 (EDJ 2013/58481) ha establecido como doctrina jurisprudencial que la guarda y custodia compartida ha de considerarse como el régimen normal y más conveniente para el menor.

Palabras clave: Guarda y custodia; interés del menor; crisis matrimoniales; corresponsabilidad parental

Abstract: Legal certainty regarding custody advice establish common performance criteria. The objective is the protection of the interests of the child, guiding principle in this matter. The STS April 29, 2013 (EDJ 2013/58481) has been established as legal doctrine that shared custody is to be regarded as the normal regime and more convenient for the child.

Key words: Custody; interest of the child; marital crisis; parental responsibility.

Recepción original: 28/04/2014

Aceptación original: 26/05/2014

\section{APUNTES PREVIOS: LA RELEVANCIA DE LOS PRONUNCIAMIENTOS SOBRE GUARDA Y CUSTODIA}

La ordenación de las relaciones entre el menor y sus progenitores ante la desintegración familiar se efectúa, de ordinario, mediante el correspondiente pronunciamiento judicial sobre guarda y custodia ${ }^{2}$. Medidas, por otra parte, de gran repercusión tanto en el aspecto personal como en el patrimonial ${ }^{3}$, por lo que resultan una de las cuestiones más controvertidas. Así mismo, es necesario tener en cuenta que nuestro ordenamiento jurídico consagra la igualdad no solo como derecho fundamental ${ }^{4}$, sino también como valor superior ${ }^{5}$ que debe

${ }^{2}$ Incluso en el procedimiento consensual, dado que el convenio regulador ha de ser aprobado judicialmente.

${ }^{3}$ Nos referimos, fundamentalmente, a la atribución del uso del domicilio y ajuar familiar y la pensión de alimentos.

${ }^{4}$ Artículo $14 \mathrm{CE}$.

${ }^{5}$ Artículo 1.1 CE. 
presidir toda actuación pública. Todo ello aconseja unificar los criterios de actuación sobre la materia, a modo de protocolo al que puedan remitirse los operadores jurídicos. Dicha seguridad o certeza legal y judicial se hace más evidente dada la coexistencia de la normativa estatal con la de nuestras Comunidades Autónomas, si bien se reclama también ante la diversidad de criterios seguidos en territorio común.

La fórmula para lograr esa deseada unificación de criterios no puede ser otra que la elaboración, consolidación y aplicación homogénea de la doctrina jurisprudencial del Tribunal Supremo, dado que de conformidad con lo establecido por el art 1.5 del Código Civil (en adelante, CC), la jurisprudencia complementa el ordenamiento jurídico y, por tanto, debería ser aplicada por todos y cada uno de los órganos judiciales con independencia de su ubicación dentro del territorio nacional.

En nuestro país con carácter general la guarda y custodia de los menores se ha venido atribuyendo a la madre, con el consabido régimen de visitas a favor del padre. Patrón que se mantiene en la actualidad según informe sobre porcentajes de atribución de la guarda y custodia publicado por el INE en relación con el año 2012, al cual haremos mención más adelante. Sin embargo, es evidente que el sustrato social en el que se fundamentaba tradicionalmente la atribución de la guarda y custodia a la madre ha variado de forma sustancial, puesto que en la actualidad tanto el hombre como la mujer trabajan fuera del hogar y, así mismo, comparten las tareas domésticas y el cuidado de los hijos, con la ayuda inestimable de los abuelos. Tal vez por ello cada vez son más los varones que solicitan la atribución de la guarda y custodia de sus hijos menores, bien de forma exclusiva, bien para compartirla con la madre. En definitiva, el hombre ya no se conforma con «visitar» a sus hijos y tenerlos esporádicamente en su compañía, sino que exige compartir sus cuidados y educación en términos de estricta igualdad. Los abundantes foros, páginas web y otros movimientos sociales activos en diversos ámbitos, son buena prueba de ello.

En resumen, la sociedad española actual está demandando un cambio radical en esta materia para que la guarda y custodia de los hijos menores de edad se reparta entre sus progenitores en términos de estricta igualdad y sin discriminación alguna por razón de sexo, tal como proclama el artículo 14 de la vigente Constitución. No podemos olvidar que, conforme establece el artículo 3.1 del CC, uno de los parámetros a tener en cuenta en la interpretación y aplicación de la Ley es, precisamente, la realidad social del tiempo en que ha de ser aplicada. 
Aunque esa «rebelión» de los padres españoles está dando sus frutos tanto en el ámbito judicial ${ }^{6}$, como en el ámbito legislativo a través de las modificaciones llevadas a cabo en determinadas legislaciones autonómi$\operatorname{cas}^{7}$, no cabe duda de que aún queda mucho camino por recorrer. $\mathrm{Y}$ el Anteproyecto de Ley de Corresponsabilidad Parental, aprobado por el Gobierno de la Nación en julio de 2013 y actualmente en trámite de audiencia, podría ser un buen punto de partida para esa andadura ${ }^{8}$.

En cualquier caso no cabe duda de que la regulación de la guarda y custodia de los menores es un tema candente y altamente conflictivo por la gran repercusión que su atribución a uno u otro de los progenitores conlleva en la práctica. Y ello porque no solo afecta a las relaciones personales, sino también a las patrimoniales, dado que con carácter general el progenitor que obtiene la guarda y custodia tiene derecho al uso y disfrute de la vivienda y ajuar familiar, así como a administrar la pensión de alimentos que el progenitor no custodio viene obligado a abonar. Y todo ello hasta tanto los hijos se independicen personal y económicamente, lo que en muchas ocasiones supone un lapso de tiempo demasiado largo. Entretanto, el otro progenitor se ve alejado de sus hijos, frecuentemente sin un lugar donde vivir y con la obligación de pagar cantidades a las que, en ocasiones, ni siquiera puede hacer frente. Impago de pensiones que, por otra parte, está tipificado como delito9.

\section{NORMATIVA VIGENTE}

Las medidas que afectan a los menores ante la ruptura de sus progenitores están contenidas básicamente en el Capítulo IX del Título I

${ }^{6}$ La STS, Sala Primera, número 257/2013, de 29 de abril, declara la doctrina jurisprudencial sobre interpretación del artículo 92.5, 6 y 7 del CC, estableciendo que debe estar fundada en el interés del menor, así como que la guarda y custodia compartida no debe considerarse algo excepcional, sino que por el contrario debe ser lo normal y deseable.

${ }^{7}$ Código de Derecho Foral de Aragón, Código Civil de Cataluña.

${ }^{8}$ El Anteproyecto fue aprobado por el Consejo de Ministros el 19 de julio de 2013, e informado por el Pleno del Consejo General del Poder Judicial el 19 de septiembre de 2013. En dicho informe se pone de manifiesto la «conveniencia» de modificar numerosos aspectos del Anteproyecto. Por su parte, la Asociación Española de Abogados de Familia elaboró un informe el 24 de octubre de 2013 en el cual directamente se proponen redacciones alternativas a la práctica totalidad de los artículos contenidos en el Anteproyecto. El Anteproyecto puede consultarse en la página web del Ministerio de Justicia www.mjusticia.gob.es

${ }^{9}$ El impago de pensiones está tipificado por el artículo 227 del Código Penal, y castigado con pena de prisión de tres meses a un año o multa de de seis a veinticuatro meses. 
del CC bajo la rúbrica «De los efectos comunes a la nulidad, separación y divorcio», así como en el Capítulo X del mismo Título, rubricado «De las medidas provisionales por demanda de nulidad, separación y divorcio». Las citadas medidas resultan aplicables tanto a los hijos matrimoniales como a los no matrimoniales, en virtud de la regla sexta del artículo 770 de la Ley de Enjuiciamiento Civil (en adelante, LEC).

Si bien la ruptura de los progenitores en nada afecta al ejercicio de la patria potestad, que seguirá ejerciéndose conjuntamente por ambos salvo que la sentencia se pronuncie sobre la privación de la misma, la custodia de los hijos menores de edad y no emancipados sí se ve afectada por la crisis familiar, debiendo pronunciarse el Juez sobre la forma en que el cónyuge apartado de los hijos podrá cumplir el deber de velar por éstos y el tiempo, modo y lugar en que podrá comunicar con ellos y tenerlos en su compañía en caso de que los cónyuges no hayan llegado a un acuerdo al respecto, así como cuando dicho acuerdo no sea aprobado judicialmente ${ }^{10}$.

De la conjunción de los artículos 92, 94 y 160 del CC se colige que nos encontramos ante un derecho-deber del progenitor, puesto que, por un lado, el primero de los preceptos citados establece que «la separación, la nulidad y el divorcio no eximen a los padres de sus obligaciones para con los hijos», de donde se deduce que continúan teniendo, entre otras, la obligación de velar por ellos, tenerlos en su compañía, alimentarlos, educarlos y procurarles una formación integral. Obligaciones todas ellas derivadas de las funciones que comprende la patria potestad ${ }^{11}$. Por otra parte, los artículos 94 y 160 del CC configuran el derecho de visitas como una verdadera facultad atribuida por la ley a favor del progenitor que no tiene la guarda y custodia de los menores, facultad que podrá limitar o suspender el juez si concurren circunstancias graves que así lo aconsejen, o bien cuando se incumplan grave o reiteradamente los deberes impuestos por la resolución judicial. En cualquier caso, el régimen de visitas debe ser entendido como un mal menor tendente a permitir unas relaciones paterno-filiales estables que haga posible cubrir las necesidades afectivas tanto del menor como del progenitor que no tiene la guarda y custodia, así como las necesidades educacionales y de estabilidad de los hijos para que la separación de los padres les afecte lo menos posible. Así se refleja en numerosas resoluciones judiciales, de entre las cuales citamos el auto de la AP de Valencia

\footnotetext{
${ }^{10}$ Artículo 103.1. ${ }^{\circ}$ del CC.

${ }^{11}$ Funciones configuradas por el artículo 154 del CC.
} 
de 27-1-1994: «Debe buscarse siempre el interés y beneficio objetivo de la menor, y es evidente que para un hijo es provechoso el contacto con uno y otro progenitor para alcanzar un desarrollo pleno y armónico».

El artículo 90 del CC establece, entre los extremos a los que necesariamente habrá de referirse el convenio regulador que los cónyuges han de acompañar a la demanda de separación o divorcio solicitados de mutuo acuerdo o por uno de ellos con el consentimiento del otro, los referentes a la determinación de la persona a cuyo cuidado hayan de quedar los hijos sometidos a la patria potestad de ambos, el ejercicio de ésta y el régimen de visitas, comunicación y estancia de los menores con el progenitor que no viva con ellos. Por su parte, el artículo 103 del mismo cuerpo legal hace lo propio en relación con las medidas provisionales que habrá de acordar el juez en defecto de acuerdo de ambos cónyuges. Finalmente, el artículo 91 impone al Juez la obligación de establecer dichas medidas en las sentencias de nulidad, separación o divorcio, o en ejecución de las mismas, cuando no haya acuerdo entre los progenitores o bien el mismo no sea aprobado.

En la actualidad las medidas sobre guarda y custodia de los hijos menores pueden quedar fijadas de las tres formas que se exponen a continuación:

\section{Orden de protección}

Entre las diversas medidas que cabe incluir en la orden de protección que regula el artículo 544-ter de la Ley de Enjuiciamiento Criminal, el apartado 7 del citado precepto legal incluye las de atribución del uso y disfrute de la vivienda familiar, determinar el régimen de custodia, visitas, comunicación y estancia con los hijos y el régimen de prestación de alimentos. Solo cabe acordarlas cuando no existan previamente y tienen una vigencia inicial de treinta días. Si durante ese plazo se incoa un procedimiento de familia ante el orden civil, la vigencia de las medidas adoptadas en el ámbito penal se amplía durante los treinta días siguientes a la presentación de la demanda, debiendo ser ratificadas, modificadas o dejadas sin efecto por el juez civil en ese término. 


\section{Guarda y custodia consensuada}

Es la que pactan los progenitores en el convenio regulador al que se refiere el artículo 90 del CC, o bien mediante el acuerdo al que pueden llegar en la comparecencia de medidas previas ${ }^{12}$, medidas provisionales ${ }^{13}$, o bien en la vista del proceso de nulidad, separación o divorcio $^{14}$. Alcanzado el acuerdo, y previo informe no vinculante del Ministerio Fiscal, el juez debe acordar el ejercicio compartido de la guarda y custodia, tal como establece el artículo 92.5 del CC. Ahora bien, no procederá en ningún caso la guarda conjunta en caso de que alguno de los progenitores esté incurso en un procedimiento penal por alguno de los delitos que se relacionan en el apartado 7 del mismo precepto legal, ni cuando existan indicios fundados de violencia doméstica.

La medida sobre guarda y custodia de los hijos menores viene regulada en el apartado A) del artículo 90 del CC en los siguientes términos: «El convenio regulador a que se refieren los artículos 81 y 86 de este Código deberá contener, al menos, los siguientes extremos: A) El cuidado de los hijos sujetos a la patria potestad de ambos, el ejercicio de ésta y, en su caso, el régimen de comunicación y estancia de los hijos con el progenitor que no viva habitualmente con ellos».

Por tanto, y salvo los casos excluidos por el artículo 92.7 del CC, la guarda y custodia de los menores puede distribuirse de mutuo acuerdo entre ambos progenitores como tengan por conveniente, sin perjuicio del necesario refrendo judicial cuyo objetivo es garantizar que se tutelen convenientemente los intereses de los menores implicados. Las distintas posibilidades pueden resumirse como sigue:

- Atribuir la guarda y custodia de todos los hijos menores íntegramente a uno de los progenitores.

- Atribuir la guarda y custodia de uno o varios hijos a la madre y la del resto al padre.

- Distribuir la guarda y custodia entre ambos progenitores de forma que los menores permanezcan un determinado tiempo con cada uno de ellos en sus respectivos domicilios (15 días, un mes, seis meses, etc.).

\footnotetext{
${ }^{12}$ Artículo 771.2 de la LEC.

${ }^{13}$ Artículo 773.3 de la LEC.

${ }^{14}$ Artículo 774.1 de la LEC.
} 
- Establecer un domicilio para los hijos en el cual se vayan alternando los padres temporalmente para ejercer la guarda y custodia.

Partiendo del modelo de guarda y custodia elegido, los progenitores habrán de pactar también los restantes extremos que atañen a los hijos menores, en particular cuál será su domicilio, el pago de los gastos ordinarios y extraordinarios y el régimen de visitas del progenitor no custodio, en su caso.

El procedimiento consensual está regulado en el artículo 777 de la LEC. Presentada la demanda junto con la propuesta de convenio regulador, y previa ratificación de los cónyuges en la petición de separación o divorcio, el tribunal recabará informe del Ministerio Fiscal sobre los términos del convenio relativos a los hijos. Practicada la prueba propuesta por los cónyuges y la que el tribunal considere necesaria $^{15}$, el tribunal dictará sentencia concediendo o denegando la separación o el divorcio y pronunciándose sobre el convenio regulador presentado. Este último pronunciamiento puede consistir en:

- Aprobar el mismo, cuando estime que tutela suficientemente el interés de los menores.

- No aprobarlo en todo o en parte. En este caso el tribunal concederá a las partes un plazo de diez días para proponer un nuevo convenio. Si el documento reformado tampoco es aprobado, el tribunal dictará auto estableciendo las medidas que considere oportunas.

La resolución judicial que apruebe en su totalidad la propuesta de convenio regulador solo podrá ser recurrida, en interés de los hijos menores o incapacitados, por el Ministerio Fiscal. La que deniegue la separación o el divorcio, y la que acuerde alguna medida que se aparte de los términos del convenio propuesto por los cónyuges, podrá ser recurrida en apelación. Por último, las medidas así adoptadas podrán ser modificadas bien de mutuo acuerdo, bien en proceso contencioso ${ }^{16}$.

\section{Guarda y custodia judicialmente determinada}

Cuando no existe acuerdo entre los progenitores el régimen de guarda y custodia ha de ser necesariamente establecido por el tribu-

${ }^{15}$ Incluida, si procede, la exploración de los menores.

${ }^{16}$ Artículo 777 de la LEC. 
nal competente aplicando el artículo 92 del CC que, resumidamente, establece lo siguiente:

- Que el juez puede acordar la privación de la patria potestad, así como decidir que la misma se ejerza total o parcialmente por uno de los progenitores.

- Que la guarda y custodia compartida se acordará siempre que exista acuerdo entre ambos progenitores (inicial o sobrevenido), o bien, de forma excepcional, a instancia de una de las partes y previo informe del Ministerio Fiscal.

- Que en ningún caso procederá la guarda conjunta cuando alguno de los progenitores esté incurso en un proceso penal por alguno de los delitos relacionados en el apartado 7 del citado artículo, ni cuando existan indicios fundados de violencia doméstica.

- Que antes de pronunciarse sobre la guarda y custodia el juez debe recabar informe del Ministerio Fiscal, oír a los menores, valorar las alegaciones de las partes y la prueba practicada, así como la relación que los padres mantengan entre sí y con sus hijos.

Los procedimientos establecidos en la LEC para la adopción de medidas son los que se exponen a continuación. En todos los casos, las medidas adoptadas son inmediatamente ejecutivas dado que, por un lado, el auto de medidas previas o provisionales no admite recurso alguno ${ }^{17} ; \mathrm{y}$, por otro lado, los recursos que puedan interponer las partes contra la sentencia que pone fin al procedimiento no suspende la eficacia de las medidas que se hubieran adoptado en dicha sentencia ${ }^{18}$. Por lo que se refiere a su ejecución forzosa, el artículo 776 de la LEC remite a las normas generales establecidas en el Libro III de la misma Ley, con las especialidades que se detallan en el propio artículo ${ }^{19}$.

${ }^{17}$ Artículos 771.4, 772, y 773.3, todos ellos de la LEC.

${ }^{18}$ Artículo 774.5 de la LEC.

${ }^{19}$ Las especialidades de ejecución consisten, básicamente, en: 1) La posibilidad de imponer multas coercitivas sin límite de tiempo; 2) No procede la sustitución automática en caso de incumplirse obligaciones pecuniarias; 3) El incumplimiento reiterado del régimen de visitas por cualquiera de los progenitores puede conllevar la modificación del régimen de guarda y custodia; 4) En caso de ejecución de gastos extraordinarios que no estén expresamente contemplados en las medidas, es necesaria la declaración judicial previa de que la cantidad reclamada tiene el carácter de gasto extraordinario. 
a) Medidas previas a la demanda ${ }^{20}$.-El cónyuge que se proponga demandar la nulidad, separación o divorcio de su matrimonio puede solicitar los efectos y medidas a que se refieren los artículos 102 y 103 del CC, entre las cuales se encuentra la que es objeto de estudio. El procedimiento aplicable es el previsto en el artículo 771 de la LEC que, resumidamente consiste en que el Secretario judicial cita a las partes a una comparecencia dentro de los diez días siguientes; si no hay acuerdo o el mismo no se aprueba judicialmente, se oye a las partes y se practican las pruebas que procedan. Si alguna de ellas no puede practicarse en el acto, se practicará dentro del plazo de diez días. Seguidamente el tribunal resuelve mediante auto, contra el que no cabe recurso alguno.

Las medidas así acordadas solo subsisten si se interpone la demanda de nulidad, separación o divorcio dentro de los treinta días siguientes, en cuyo caso se unirán las actuaciones sobre adopción de medidas, pudiendo el tribunal completar o modificar las mismas previa celebración de nueva comparecencia ${ }^{21}$.

b) Medidas provisionales.-Una vez interpuesta y admitida a trámite la demanda de nulidad, separación o divorcio, se producen por ministerio de la Ley los efectos a que se refiere el artículo 102 del CC $^{22}$ y pueden adoptarse todas o alguna de las medidas contempladas en el artículo 103 del CC, a petición de parte y con carácter provisional entretanto se tramita el procedimiento principal ${ }^{23}$. En cuanto al procedimiento, el artículo 773 de la LEC remite al mismo que hemos expuesto en relación con las medidas provisionalísimas.

También el demandado puede solicitar en la contestación a la demanda que se adopten medidas provisionales, cuando las mismas no hayan sido fijadas anteriormente ni se haya solicitado su adopción por la parte demandante. En este caso la petición se sustanciará en la vista principal siempre que la misma se celebre en el plazo de diez días, y si no es posible hacerlo en el breve plazo indicado se convocará igualmente a ambos cónyuges a la comparecencia antes referida.

${ }^{20}$ También denominadas en la práctica forense «provisionalísimas».

${ }^{21}$ Artículo 772 de la LEC.

${ }^{22}$ Los cónyuges pueden vivir separados, cesa la presunción de convivencia conyugal, quedan revocados los consentimientos y poderes que cualquiera de los cónyuges hubiera otorgado al otro y cesa la posibilidad, salvo pacto en contrario, de vincular los bienes privativos del otro cónyuge en el ejercicio de la potestad doméstica.

${ }^{23}$ No es posible la adopción de medidas provisionales cuando ya se hayan adoptado anteriormente, bien como previas a la interposición de la demanda matrimonial, bien como medidas cautelares en el proceso penal ex artículo 544-ter de la Ley de Enjuiciamiento Criminal. 
Las medidas provisionales mantendrán su vigencia hasta que sean sustituidas por las fijadas en la sentencia que ponga fin al proceso de nulidad, separación o divorcio.

c) Medidas definitivas.-Son aquellas que se adoptan en la sentencia que pone fin al proceso de nulidad, separación o divorcio. El procedimiento es el previsto en los artículos 770 y 774 de la LEC.

En todos los casos, la intervención del Ministerio Fiscal es preceptiva siempre que alguno de los cónyuges o sus hijos sean menores, incapacitados o ausentes ${ }^{24}$. Igualmente es preceptiva la intervención de abogado y procurador, si bien ambos cónyuges pueden valerse de una sola defensa y representación en los supuestos consensuados ${ }^{25}$. No obstante, cuando alguna de las partes solicite la ejecución forzosa de las medidas pactadas, el Secretario requerirá a la otra parte para que designe nuevo abogado y procurador.

\section{CRITERIOS ACTUALES Y JURISPRUDENCIA RELACIONADA CON LA ATRIBUCIÓN DE LA GUARDA Y CUSTODIA}

De conformidad con la normativa vigente, en esta materia el criterio que debe primar sobre cualquier otro es el supremo interés del menor. Ahora bien, lo realmente dificultoso es concretar ese principio general o concepto indeterminado en cada caso para así poder decantarse por un concreto régimen de guarda y custodia.

En este sentido, la STS, Sala 1. ${ }^{a}$ número 495/2013, de 19 de julio de 2013, ha interpretado el mismo de la siguiente forma: «Es decir, se prima el interés el menor y este interés, que ni el artículo 92 del Código Civil ni el artículo 9 de la Ley Orgánica 1/1996, de 15 de enero, de Protección Jurídica del Menor, definen ni determinan, exige sin duda un compromiso mayor y una colaboración de sus progenitores tendente a que este tipo de situaciones se resuelvan en un marco de normalidad familiar que saque de la rutina una relación simplemente protocolaria del padre no custodio con sus hijos que, sin la expresa colaboración del otro, termine por desincentivarla tanto desde la relación del no custodio con sus hijos, como de estos con aquel».

A priori, pues, y salvo en determinados supuestos muy concretos en los cuales no resulte aconsejable la convivencia del menor con alguno de sus progenitores por existir una total y absoluta falta de inte-

\footnotetext{
${ }^{24}$ Artículo 749 de la LEC.

${ }^{25}$ Artículo 750 de la LEC.
} 
rés hacia el niño o bien por algún otro motivo insoslayable ${ }^{26}$, el supremo interés del menor debería hallarse en el mantenimiento de un status lo más parecido posible al que tenía antes de la ruptura de sus padres, de forma que su relación con ambos progenitores y sus respectivas familias cambie lo menos posible. Probablemente esta es la única forma de que el desarrollo físico y emocional del niño sea el adecuado. Y para lograr ese objetivo es evidente que se imponen los regímenes de guarda y custodia compartida, sin perjuicio de adecuar los pronunciamientos a las condiciones de todo tipo que concurran en cada caso concreto.

Tal como refleja en la exposición de motivos del Anteproyecto de Ley de Corresponsabilidad Parental, la Convención sobre los Derechos del Niño obliga a los Estados a respetar su derecho a mantener relaciones personales y contacto directo con ambos padres de modo regular, salvo que fuera contrario al interés superior del niño.

Ese parece ser también el sentimiento generalizado de la población española en la actualidad, siendo muchas las personas de los ámbitos más diversos que se han pronunciado en público en este sentido. A título de ejemplo se trascriben parcialmente las manifestaciones efectuadas recientemente por el Magistrado de la Sala Primera del Tribunal Supremo Sr. Seijas Quintana ${ }^{27}$ : «El derecho de familia debe adaptarse a la realidad. Bajo esta premisa el magistrado de la Sala Primera del Tribunal Supremo, José Antonio Seijas Quintana, defendió ayer durante una conferencia ofrecida en el Ateneo Jovellanos las bondades de la custodia compartida. "Posiblemente esto no sea la panacea de los problemas de la ruptura familiar, pero a mi juicio es muy útil y beneficia sobre todo a los menores, que son los que hay que proteger. Hay otros sistemas igual de defendibles pero debería ir imponiéndose poco a poco la custodia compartida», argumentaba el juez admitiendo que aún «se están dando los primeros pasos en este campo»».

Y es que, pese a las bondades que el régimen de guarda y custodia compartida ofrece sobre el papel, la realidad es que la inmensa mayoría de las resoluciones judiciales siguen atribuyendo la guarda y custodia de los menores a la madre ${ }^{28}$, frente a las escasas resoluciones que optan por la guarda compartida ${ }^{29}$, y las casi simbólicas que se la

\footnotetext{
${ }^{26}$ Enfermedades graves o ausencias prolongadas del progenitor, drogodependen-

${ }^{27} \mathrm{http}: / / w w w . l n e . e s / g i j o n / 2013 / 12 / 13 /$ seijas-quintana-aboga-imponer-guardia/1513904.html. Fecha consulta: 21/04/2014.

${ }^{28}$ En el $81,7 \%$ de los casos.

${ }^{29} \mathrm{El} 12,3 \%$ de los casos.
} cias, etc. 
atribuyen al padre ${ }^{30}$. En el resto de los casos se le atribuye a otros familiares o a instituciones públicas ${ }^{31}$. Sin embargo, como también hemos expuesto anteriormente en la actualidad no existe justificación objetiva alguna para que esos patrones se sigan perpetuando. Es más, son muchos los motivos que abogan precisamente porque la guarda y custodia se reparta entre ambos progenitores de forma más igualitaria, entre otros:

- Es la sociedad actual la que propugna el cambio, y su demanda debe ser tenida en cuenta como criterio de interpretación de la normativa aplicable 32 .

— De conformidad con nuestra vigente Constitución la igualdad es un valor superior de nuestro ordenamiento jurídico33, está absolutamente vetada la discriminación por razón de sexo34 y los poderes públicos están obligados a promover las condiciones necesarias para que la igualdad sea real y efectiva35.

- El mantenimiento del rol de cuidadora de los hijos en la mujer entorpece gravemente el proceso de igualación de sexos, impidiendo su inserción socio-laboral en condiciones de igualdad con el hombre y, consiguientemente, generar derecho a prestaciones por desempleo, incapacidad permanente o jubilación.

Podríamos continuar esbozando las razones que justifican un cambio radical en la materia, pero la realidad es que es que ni el legislador estatal se ha atrevido a coger al toro por los cuernos en el Anteproyecto de Ley Sobre el Ejercicio de la Corresponsabilidad Parental en caso de nulidad, separación y divorcio actualmente en trámite, ni las legislaciones autonómicas más vanguardistas en la materia han conseguido un cambio sustancial de tendencia. A título de ejemplo, en el año 2012 la guarda y custodia compartida se estableció en el $21 \%$ de los casos en Cataluña y en el $19 \%$ en el caso de Aragón, mientras que su atribución a la madre alcanzó el 74\% en ambas Comunidades $^{36}$.

${ }^{30} \mathrm{El} \mathrm{5,3 \%}$ de los casos.

31 Todos los datos proceden del Instituto Nacional de Estadística y se refieren al año 2012.

${ }^{32}$ El artículo 3 del CC establece como criterio de interpretación de las normas jurídicas «la realidad social del tiempo en que han de ser aplicadas».

${ }^{33}$ Artículo 1.1 CE.

${ }^{34}$ Artículo $14 \mathrm{CE}$.

${ }^{35}$ Artículo 9.2 CE.

${ }^{36}$ Fuente: Estudio del Instituto Nacional de Estadística referente al año 2012. 


\section{Supuestos en los que resulta posible su adopción}

De conformidad con la actual redacción del artículo 92 del CC $^{37}$ la guarda y custodia compartida puede acordarse en dos supuestos: a) Cuando lo soliciten ambos progenitores ${ }^{38}$; b) Cuando, a pesar de no existir acuerdo al respecto, el Juzgador considere que de esa forma se tutela más eficazmente el supremo interés del menor ${ }^{39}$. Por otra parte, a partir de que el TC declarara la nulidad del inciso «favorable» contenido en el apartado 8 del art $92^{40}$, corresponde exclusivamente al Juez valorar la conveniencia o no de acordar este régimen, con independencia del sentido en el que se pronuncie el Ministerio Fiscal en su preceptivo informe.

La STS 28 septiembre 2009 (EDJ 2009/229007), ha dejado sentado que «...la normativa relativa al interés del menor tiene características de orden público, por lo que debe ser observada necesariamente por los jueces y tribunales en las decisiones que se tomen en relación a los menores, como se afirma en la STC 141/2000, de 29 mayo, que lo califica como "estatuto jurídico indisponible de los menores de edad dentro del territorio nacional", destacando como relevantes a estos efectos la Convención de las NNUU sobre los Derechos del Niño, de 1989, ratificada por España en 1990, la Carta europea de los Derechos del Niño del Parlamento Europeo (Resolución A 3-0172/92, de 8 julio) y la LO 1/1996, de Protección Jurídica del Menor. Asimismo SSTC 143/1990, 187/1996 y 114/1997, así como el ATC 28/2001, de 1 febrero».

Pero no obstante esta supremacía del interés del menor, la complejidad de la cuestión se manifiesta, básicamente, en dos aspectos: En primer lugar, determinar cuál es el supremo interés del menor en cada caso concreto: Tarea que no resulta en absoluto sencilla, sobre todo en el marco de conflictividad familiar en la que, normalmente, se incardina. Es inevitable que cuando se produce la ruptura entre los progenitores ambos dediquen sus esfuerzos a salvaguardar sus propios intereses, relegando los de los menores a un segundo plano. Del estudio del derecho comparado se extrae la conclusión, asumida por el $\mathrm{TS}^{41}$, de que deben tomarse en cuenta criterios como, por ejemplo, la práctica anterior de los progenitores en sus relaciones con el menor; sus aptitudes personales; los deseos manifestados por

\footnotetext{
${ }^{37}$ Redactada por Ley 15/2005.

${ }^{38}$ Párrafo 5.

${ }^{39}$ Párrafo 8.

${ }^{40}$ STC de 17 octubre 2012.

${ }^{41}$ STS de 8 octubre 2009.
} 
los menores competentes; el número de hijos; el cumplimiento por parte de los progenitores de sus deberes en relación con los hijos y el respeto mutuo en sus relaciones personales y con otras personas que convivan en el hogar familiar; los acuerdos adoptados por los progenitores; la ubicación de sus respectivos domicilios; los horarios y actividades de ambos; el resultado de los informes exigidos legalmente $y$, en general, cualquier otro que permita lograr el objetivo perseguido, esto es: Establecer un régimen de guarda y custodia que permita a los menores llevar una vida lo más normalizada posible teniendo en cuenta que la convivencia a partir de la ruptura necesariamente ha de ser más compleja.

La segunda cuestión no es menos problemática, puesto que se trata de dilucidar quién es la persona o el órgano judicial al que le corresponde la facultad de apreciar ese supremo interés. En los procedimientos consensuales prevalece el criterio de los progenitores, conforme resulta del apartado 5 del art 92 del $\mathrm{CC}^{42}$. Pero cuando el consenso no es posible, la cosa se complica. Como dice la STS 8 de octubre 2009 (EDJ 2009/234619), «...el problema procesal se plantea en torno al órgano que debe apreciar dicho interés, porque como señala la doctrina más autorizada, en esta cuestión, la discusión sobre si se ha aplicado o no la norma fundando la decisión en el interés del menor tiene aspectos casacionales, mientras que la delimitación de la realidad que determina en cada caso concreto cuál es el interés del menor, no los tendrá. Este Tribunal ha considerado que por tratarse de una facultad discrecional del juzgador, en el segundo aspecto no cabe impugnación casacional, a menos que en las actuaciones figuren "esas graves circunstancias que aconsejen otra cosa"...».

Dicho de otra forma: Dado que la «delimitación de la realidad»o fijación de hechos probados corresponde a los órganos judiciales de instancia, y el interés del menor depende de la situación material casuística, los pronunciamientos sobre medidas solo podrán ser combatidos ante el TS en los casos siguientes: 1) A través del recurso extraordinario por infracción procesal, cuando la sentencia que se dicte incurra en alguna de las infracciones susceptibles de fundamentar este recurso conforme a las normas que le son propias. Habrá que acudir por tanto a este remedio siempre que se considere que la situación de hecho que se refleja en la resolución judicial no se corresponde con la realidad. 2) A través del recurso de casación cuando, a pesar de que la delimitación de la realidad realizada por el

${ }^{42}$ Sin perjuicio de su apartado 6 . 
órgano a quo sea acertada, no se haya fundado la decisión en el supremo interés del menor.

Por consiguiente, en la praxis resulta decisivo que en el procedimiento judicial se despliegue la actividad probatoria necesaria para acreditar la situación de hecho. Y en el supuesto de que las pruebas propuestas sean inadmitidas, habrán de utilizarse cuantos recursos y demás remedios procesales sean procedentes en derecho, a fin de mantener la posibilidad de formular recurso extraordinario por infracción procesal contra la resolución que se dicte.

Sin perjuicio de lo anterior, no podemos olvidar que tanto las cuestiones formales como las materiales son susceptibles de ser revisadas por las AAPP a través del recurso de apelación ${ }^{43} \mathrm{y}$, por lo tanto, será la Audiencia competente la que en la mayoría de las ocasiones dicte la resolución definitiva ${ }^{44}$.

En suma, la determinación de cuál es el interés del menor en cada caso concreto corresponde a los progenitores ${ }^{45}$ en los procedimientos consensuales, mientras que en los contenciosos corresponderá:

1. Al juzgado de primera instancia, cuando ambas partes se aquieten con la sentencia dictada.

2. A la AP correspondiente, cuando alguna o ambas partes interpongan recurso de apelación.

3. Al TS, siempre que proceda recurso extraordinario y las partes efectivamente lo interpongan.

\section{Aspectos concretos ya resueltos por el Tribunal Supremo}

La Sala Primera del $\mathrm{TS}^{46}$ se ha pronunciado ya sobre numerosas cuestiones relacionadas con el tema que nos ocupa. Existe, por tanto, un cuerpo de doctrina jurisprudencial que, además de permitir fundamentar en su vulneración el recurso de casación por interés casacional, es complemento del ordenamiento jurídico ${ }^{47} \mathrm{y}$, como tal, ha de ser aplicada

${ }^{43}$ Así resulta del art 456.1 de la LEC.

${ }^{44}$ Así será no solo cuando no concurran los requisitos exigidos para la interposición del recurso de casación fundado en la existencia de interés casacional, sino también cuando, aún concurriendo, la parte perjudicada por la resolución judicial no pueda asumir su coste económico.

${ }^{45}$ Con la limitaciones antes expuestas.

${ }^{46} \mathrm{Al}$ interpretar y aplicar el art 92 del CC en cumplimiento de su labor nomofiláctica y uniformadora.

${ }^{47}$ Artículo 1.6 del CC. 
por el resto de los órganos judiciales. Sin pretensiones de exhaustividad, al día de hoy existe jurisprudencia sobre las siguientes materias ${ }^{48}$ :

\section{A) Excepcionalidad}

La STS 22 de julio 2011 (EDJ 2011/155183), interpreta el adjetivo «excepcional» del art 92.8 del CC, afirmando que este apartado hay que ponerlo en relación con el 5 y, por lo tanto, la excepcionalidad está referida a la falta de acuerdo entre los cónyuges, no a que existan circunstancias específicas.

Dice la citada resolución: «El texto actualmente vigente del art 92.8 CC, redactado por Ley 15/2005, admite la posibilidad de que el juez establezca como forma de protección de los menores, la guarda y custodia compartida, aun cuando no haya sido pedida por ambos progenitores. La interpretación que se deriva de su texto literal es clara. El redactado de dicho párrafo 8 dice: "Excepcionalmente, aun cuando no se den los supuestos del apartado cinco de este artículo, el Juez, a instancia de una de las partes, con informe favorable del Ministerio Fiscal, podrá acordar la guarda y custodia compartida fundamentándola en que solo de esta forma se protege adecuadamente el interés del menor". La excepcionalidad a que se refiere el inicio del párrafo 8 , debe interpretarse, pues, en relación con el párrafo cinco del propio art. que admite que se acuerde la guarda y custodia compartida cuando así lo soliciten ambos progenitores o uno con el acuerdo del otro. Si no hay acuerdo, el art 92.8 CC no excluye esta posibilidad, pero en este caso, debe el Juez acordarla "fundamentándola en que solo de esta forma se protege adecuadamente el interés superior del menor". De aquí que no resulta necesario concretar el significado de la "excepcionalidad", a que se refiere el art 92.8 CC, ya que en la redacción del artículo aparece claramente que viene referida a la falta de acuerdo entre los cónyuges sobre la guarda compartida, no a que existan circunstancias específicas para acordarla».

B) Relación entre los progenitores

La misma Sentencia citada en el apartado anterior establece que las relaciones entre los cónyuges, por sí mismas, no resultan relevan-

${ }^{48}$ Reflejada, por tanto, en al menos dos SSTS, aún cuando se cite solamente una. 
tes para determinar cuál sea el régimen de guarda y custodia más conveniente ${ }^{49}$.

En particular advierte que «de aquí que las relaciones entre los cónyuges por sí solas no son relevantes ni irrelevantes para determinar la guarda y custodia compartida. Solo se convierten en relevantes cuando afecten, perjudicándolo, el interés del menor».

\section{C) Régimen normal y deseable}

La transcendental STS 29 abril 2013 (EDJ 2013/58481) establece que la guarda y custodia compartida no es excepcional, sino que debe considerarse la mejor solución porque permite al menor seguir relacionándose del modo más razonable con ambos progenitores.

En efecto, tras razonar profusamente las razones en que se fundamenta, dicha sentencia establece lo siguiente: «3. ${ }^{\circ}$ Se declara como doctrina jurisprudencial que la interpretación de los arts. 92.5, 6 y 7 CC debe estar fundada en el interés de los menores que van a quedar afectados por la medida que se deba tomar, que se acordará cuando concurran criterios tales como la práctica anterior de los progenitores en sus relaciones con el menor y sus aptitudes personales; los deseos manifestados por los menores competentes; el número de hijos; el cumplimiento por parte de los progenitores de sus deberes en relación con los hijos y el respeto mutuo en sus relaciones personales; el resultado de los informes exigidos legalmente, y, en definitiva, cualquier otro que permita a los menores una vida adecuada, aunque en la práctica pueda ser más compleja que la que se lleva a cabo cuando los progenitores conviven. Señalando que la redacción del art 92 no permite concluir que se trate de una medida excepcional, sino que al contrario, habrá de considerarse normal e incluso deseable, porque permite que sea efectivo el derecho que los hijos tienen a relacionarse con ambos progenitores, aun en situaciones de crisis, siempre que ello sea posible y en tanto en cuanto lo sea».

${ }^{49}$ La lógica evidencia que, si se ha producido la ruptura, es precisamente porque las relaciones entre los progenitores se han deteriorado, pero ello no debe conllevar automáticamente la exclusión del régimen de guarda y custodia compartida. Si así fuera, las malas relaciones podrían ser propiciadas deliberadamente por el progenitor al que no interese el régimen de guarda y custodia compartida. 
D) Imprescindible petición de parte

También la STS 29 abril 2013 (EDJ 2013/58481) determina la necesidad de que la guarda y custodia compartida sea solicitada, al menos, por uno de los progenitores: «En ambos $\operatorname{casos}^{50}$, un requisito esencial para acordar este régimen es la petición de uno, al menos de los progenitores: si la piden ambos, se aplicará el párrafo quinto, y si la pide uno solo y el juez considera que, a la vista de los informes exigidos en el párrafo octavo, resulta conveniente para el interés del niño, podrá establecerse este sistema de guarda. El CC, por tanto, exige siempre la petición de al menos uno de los progenitores, sin la cual no podrá acordarse».

E) No basta una motivación puramente retórica

En relación con la motivación de las resoluciones judiciales sobre guarda y custodia, la STS 7 julio 2011 (EDJ 2011/146903), después de citar la doctrina tanto propia como del TC sobre la necesidad de motivar las resoluciones judiciales en general, concluye afirmando en los siguientes términos, la insuficiencia de una motivación puramente retórica: «La motivación contenida en la sentencia recurrida no tiene en cuenta más que de forma retórica, el interés del menor, por lo que no es suficiente para justificar la negativa al establecimiento de la guarda y custodia compartida...De acuerdo con el informe del Ministerio Fiscal que apoya el recurso extraordinario por infracción procesal, esta Sala concluye que falta la motivación suficiente para considerar cumplido el deber constitucional de motivación, al fundarse la sentencia recurrida únicamente en forma nominal en el interés del menor, que después no aplica para resolver el recurso».

F) No accede a la casación la valoración de las circunstancias concretas

También de forma reiterada se ha pronunciado el Alto Tribunal sobre la materia revisable en casación: «Así pues, de conformidad con la doctrina jurisprudencial citada tendrán acceso a la casación las cuestiones relativas a la aplicación de la norma sustantiva (función nomofiláctica), pero no la apreciación de la prueba o valoración de las cir-

${ }^{50}$ Art 92.5 y 8 CC. 
cunstancias que concurran en cada caso concreto. Así resulta por ejemplo de la STS 323/2012, de 25 de mayo. Aplicando estos argumentos, las sentencias recaídas en casos en que se discute la guarda y custodia compartida, señalan que la doctrina de la Sala se ha pronunciado en el sentido que en estos recursos solo puede examinarse si el Juez $a$ $q u o$ ha aplicado correctamente el principio de protección del interés del menor, motivando suficientemente a la vista de los hechos probados en la sentencia que se recurre, la conveniencia de que se establezca o no este sistema de guarda (SSTS 614/2009, de 28 septiembre, 623/2009, de 8 octubre, 469/2011, de 7 julio, 641/2011, de 27 septiembre y 154/2012, de 9 marzo, 579/2011, de 22 julio y 578/2011, de 21 julio)».

G) Determinar el domicilio del menor es una facultad inherente a la patria potestad

La determinación del domicilio del menor es una de las facultades inherentes a la patria potestad y, por ello, corresponde a ambos progenitores la decisión al respecto. En caso de desacuerdo, resolverá el juez conforme establece el art 156 del CC, pero sin perder de vista el supremo interés del menor, pudiendo dar lugar a un cambio de guarda y custodia.

Lo anterior resulta de lo dilucidado por la STS 26 octubre 2012 (EDJ 2012/232597): «Es cierto que la CE, en su art 19, determina el derecho de los españoles a elegir libremente su residencia, y a salir de España en los términos que la ley establezca. Pero el problema no es este. El problema se suscita sobre la procedencia o improcedencia de pasar la menor a residir en otro lugar, lo que puede comportar un cambio radical tanto de su entorno social como parental, con problemas de adaptación. De afectar el cambio de residencia a los intereses de la menor, que deben de ser preferentemente tutelados, podría conllevar, un cambio de la guarda y custodia (...) la sentencia deja sin contenido los derechos de la hija a la protección y el cuidado que sean necesarios para su bienestar, y se soslayan los derechos y deberes de los padres que garantizan el reconocimiento del principio de que ambos tienen obligaciones comunes en lo que respecta a la crianza y desarrollo del niño (art 18.1 de la Convención sobre los Derechos del Niño, adoptada y abierta a la firma y ratificación por la Asamblea General en su resolución 44/25, de 20 de noviembre de 1989, ratificada por España el 30 de noviembre de 1990, así como Ley Orgánica 1/1996, de 15 de enero de Protección Jurídica del Menor, que incorpora a la normativa española la nueva sensibilidad hacia el mundo de la 
infancia), y también el derecho de los padres a ejercer la patria potestad aun en el caso de que vivan separados, como dice en su informe el Ministerio Fiscal, que se comparte».

H) Posibilidad de modificar anteriores medidas con fundamento en las nuevas tendencias

Por último, el TS abre la puerta a la modificación de las medidas sobre guarda y custodia adoptadas con anterioridad, con fundamento en que la actual doctrina jurisprudencial y la legislación autonómica supone una variación sustancial de las circunstancias a los efectos previstos en los artículos 91 CC y 775 LEC.

Dice así la STS 25 noviembre 2013 (EDJ 2013/239137): «A la vista de lo expuesto es razonable declarar que se ha producido un cambio de circunstancias extraordinario y sobrevenido tras la jurisprudencia citada del TC, de la que esta Sala se ha hecho eco, hasta el punto de establecer que el sistema de custodia compartida debe considerarse normal y no excepcional, unido ello a las amplias facultades que la jurisprudencia del TC fijó para la decisión de los tribunales sobre esta materia, sin necesidad de estar vinculados al informe favorable del Ministerio Fiscal. Complementario de todo ello es la reforma del CC sobre la materia y la amplia legislación autonómica favorecedora de la custodia compartida, bien sabido que todo cambio de circunstancia está supeditado a que favorezca al interés del menor».

\section{ANTEPROYECTO DE LEY SOBRE EL EJERCICIO DE LA CORRESPONSABILIDAD PARENTAL}

El texto consta de cinco artículos: El primero de ellos se desglosa en dieciocho apartados mediante los cuales se modifican los artículos 90 a 97, 100, 102, 103, 142, 152, 156, 163, 170 y 1396, y se introduce un nuevo artículo 92 bis, todos ellos del CC; el artículo segundo se compone de once apartados que atañen a la modificación de los artículos 770, 771, 774, 775 a 777 y 807 a 811 de la LEC; los artículos tercero y cuarto del Anteproyecto afectan, respectivamente, al artículo 38 de la Ley de 8 de junio de 1957, de Registro Civil, y 40 de la Ley 20/2011, de 22 de julio, de Registro Civil; y, finalmente, el artículo quinto introduce modificaciones en la Ley 5/2012, de 6 de julio, de Mediación en asuntos Civiles y Mercantiles. 
Si bien el Anteproyecto introduce modificaciones dignas de alabanza, como por ejemplo la necesidad de que los progenitores propongan un plan de ejercicio de la patria potestad conjunta tanto en los supuestos de mutuo acuerdo como en los contenciosos, en relación con la guarda y custodia la nueva regulación, además de no contener previsión alguna sobre los hijos no matrimoniales ${ }^{51}$, se queda poco menos que en agua de borrajas puesto que no conlleva cambios sustanciales.

La redacción del artículo 92 bis del CC, de nuevo cuño, es la siguiente: «1. El Juez podrá acordar, en interés de los hijos, que su guarda y custodia sea ejercitada por uno solo de los progenitores o por los dos, de forma compartida.- Podrá establecer, si lo considera conveniente para la protección del interés superior de los hijos, el ejercicio compartido de su guarda y custodia cuando así lo soliciten los padres en la propuesta de convenio regulador, cuando ambos lleguen a este acuerdo en el transcurso del procedimiento o cuando, no mediando acuerdo, cada uno de ellos inste la custodia para ambos o para sí».

La novedad estriba, pues, en que se contempla expresamente la posibilidad de que el juez establezca un régimen de guarda y custodia compartida aunque ninguno de los cónyuges la haya solicitado ${ }^{52}$. Posibilidad que, ciertamente, no está contemplada en la actual regulación; pero tampoco está prohibida, por lo que nada impide al juez acordarla en interés del menor.

Como es de ver, a pesar de las demandas sociales, de la apertura que las regulaciones autonómicas introducen en la materia y de las actuales tendencias jurisprudenciales, la nueva redacción ni tan siquiera establece la guarda y custodia compartida como la opción más deseable en defecto de acuerdo. De hecho no se decanta en ningún sentido, limitándose a dejar el arbitrio judicial sometido al dificultoso e inespecífico criterio rector del interés del menor. Es más, las restantes medidas que necesariamente han de establecerse tras la ruptura parten de la hipótesis de que la guarda y custodia se ha atribuido a uno solo de los progenitores.

Se mantiene así mismo la necesidad de recabar informe ${ }^{53}$ del Ministerio Fiscal antes de acordar el régimen de guarda y custodia, así como la exploración del menor y el dictamen de expertos, en ambos

${ }^{51}$ Ignorando el mandato contenido en el artículo 39.2 de la Constitución Española: «Los poderes públicos aseguran, asimismo, la protección integral de los hijos, iguales éstos ante la ley con independencia de su filiación...».

${ }^{52}$ Siempre, eso sí, que hayan solicitado la guarda y custodia para sí.

${ }^{53}$ No vinculante desde STC 185/2012, de 17 de octubre. 
casos si se estima necesario; incluyendo el segundo párrafo del apartado 3 del nuevo artículo un largo elenco de cuestiones a las que el juez debe prestar especial atención ${ }^{54}$. En definitiva, y al igual que en la actualidad, el juez habrá de tener en cuenta todos aquellos parámetros que le permitan identificar el supremo interés del menor para poder tutelarlo en cada caso concreto.

Pero no solo resulta criticable la nula virtualidad de la reforma para cambiar la situación actual sobre guarda y custodia. Si analizamos el apartado 5 del nuevo artículo vemos, en primer lugar, las graves consecuencias para los hijos que se derivan de que cualquiera de sus progenitores resulte condenado en sentencia firme por alguno de los ilícitos penales que se relacionan en el mismo. Y ello porque en ese caso no solo se prohíbe tajantemente al juez que atribuya al agresor la guarda y custodia individual o compartida, sino que ni tan siquiera cabe establecer un régimen de comunicación y estancia. Establece el párrafo en cuestión lo siguiente: «No procederá atribuir la guarda y custodia de los hijos, ni individual ni compartida, ni un régimen de estancia, relación y comunicación respecto de ellos, al progenitor que haya sido condenado penalmente por sentencia firme, por atentar contra la vida, la integridad física, la libertad, la integridad moral o la libertad e indemnidad sexual del otro cónyuge o de los hijos que convivan con ambos hasta la extinción de la responsabilidad penal, tras lo cual será el Juez quien deba valorar si procede tal concesión, atendiendo a los criterios señalados en los apartados anteriores y, singularmente al delito cometido, duración de la pena, reincidencia y reinserción del progenitor. Excepcionalmente, el Juez podrá establecer, si lo considera conveniente para la protección del interés superior de los menores, atendiendo a los criterios anteriores y a la peligrosidad del progenitor condenado, un régimen de estancia, relación y comunicación respecto de ellos».

Entendemos que la medida es absolutamente desorbitada, se plantea como un castigo para el progenitor y no tiene en cuenta el supremo interés del menor que, como antes se ha expuesto, está vinculado directamente con la convivencia o, al menos, relación con ambos progenitores. Evidentemente lo ideal sería que todos los niños tuvieran unos padres perfectos y que ningún menor tuviera que padecer las consecuencias de las agresiones que se puedan llegar a producir entre ellos. Pero el caso es que los niños viven en un mundo real, no ideal; y en ese mundo real por desgracia es frecuente que se produzcan dispu-

\footnotetext{
${ }^{54}$ Edad, opinión, arraigo social, escolar y familiar de los menores, posibilidad de conciliar la vida familiar y laboral, la situación de las respectivas residencias de los progenitores, la existencia de estructuras de apoyo, etc.
} 
tas e incluso agresiones en el entorno familiar. Por tanto, si esas agresiones se producen habrá que analizar el caso concreto, tener en cuenta su gravedad, las circunstancias en las en que se produzca, la situación en la que quedaría el menor si se le priva del contacto con sus progenitores, etc. En definitiva, impedir toda relación de un niño con alguno de sus progenitores o con ambos porque, por ejemplo, han sido condenados por una falta de lesiones ${ }^{55}$, es absolutamente desproporcionado y atenta contra el supremo interés del menor.

Tampoco resulta admisible que mediante ley ordinaria se supriman, restrinjan o modifiquen derechos fundamentales. Nos estamos refiriendo concretamente a la presunción de inocencia, garantizada por el artículo 24.2 de la Constitución, derecho que resulta cercenado por el párrafo segundo el artículo 92 bis, apartado 5, del Código Civil ${ }^{56}$.

Privar a un progenitor de la guarda y custodia de sus hijos con fundamento en la existencia de un proceso penal en trámite en el que todavía no se ha dictado resolución firme de condena es, sencillamente, inviable. Y ello porque, además de vulnerar el derecho a la presunción de inocencia, va en contra de los más elementales principios generales del derecho emanados de nuestro vigente ordenamiento jurídico, con la Constitución en su cúspide. Y ello por mucho que el propio artículo prevea la revisión del régimen de guarda y custodia en caso de que se dicte sentencia absolutoria o se decrete el sobreseimiento libre ${ }^{57}$, porque pueden transcurrir varios años entretanto y la relación paterno filial perdida durante ese tiempo no se puede recuperar de ningún modo. Para colmo de despropósitos, ni tan siquiera es preciso que exista un proceso penal en curso, sino que basta con que el juez civil considere que existen indicios fundados de la comisión de tales hechos.

Esta redacción hace oídos sordos también a la doctrina jurisprudencial conforme a la cual la mala relación entre los progenitores únicamente tiene relevancia a efectos de la atribución de la guarda y

${ }^{55}$ La norma habla de condena penal por sentencia firme, sin excluir las que puedan dictarse en juicios de faltas.

${ }^{56}$ «No se le atribuirá la guarda y custodia, ni individual ni compartida, cuando esté incurso en un proceso penal iniciado por la presunta comisión de violencia doméstica, de género o de cualquiera de los atentados antes referidos, y se haya dictado resolución judicial motivada en la que se constaten indicios fundados y racionales de criminalidad. La Sentencia absolutoria o el sobreseimiento libre firme dictado en el referido proceso penal será causa de revisión del régimen de guarda y custodia a petición de parte. Y tampoco procederá cuando el Juez del procedimiento civil advierta, de las alegaciones de las partes y las pruebas practicadas, la existencia de indicios fundados de la comisión de tales hechos por el progenitor, siempre que el delito no estuviera prescrito».

${ }^{57}$ La revisión no procedería en caso de sobreseimiento provisional. 
custodia compartida cuando la misma afecta, perjudicándolo, el interés de los menores ${ }^{58}$.

Y a mayor abundamiento, una vez más no se ha tenido en cuenta el supremo interés del menor, por los mismos motivos expuestos en relación con los supuestos de condena anteriormente examinados.

La exposición de motivos del Anteproyecto que comentamos pretende justificar tales medidas en el «compromiso asumido por los poderes públicos para prevenir, erradicar y castigar la violencia doméstica y de género en todos los ámbitos de la sociedad», olvidando al parecer que el bien jurídico que debe proteger esta concreta norma es el supremo interés del menor, que no tiene por qué coincidir con el interés de sus progenitores ni con los del resto de la sociedad.

De mantenerse esta redacción que criticamos abiertamente, probablemente no solo será cuestionada su constitucionalidad, sino que aumentarán de forma considerable las denuncias entre cónyuges con el fin de «inhabilitar» a su adversario y así lograr sus objetivos personales sobre guarda y custodia. Con el riesgo de que, si las denuncias son cruzadas, los menores puedan terminar al cuidado de familiares, allegados, o incluso entidades públicas, tal como prevé el apartado 6 de la norma que comentamos.

Por si todo lo anterior no fuera lo suficientemente grave, la reforma sobre guarda y custodia es abiertamente contraria a la Jurisprudencia consolidada del Tribunal Supremo ${ }^{59}$ que considera requisito esencial para acordar judicialmente el régimen de custodia compartida la petición de al menos uno de los cónyuges.

\section{CONCLUSIONES}

1. Los pronunciamientos judiciales sobre guarda y custodia repercuten notablemente en la vida de progenitores e hijos menores.

2. En aras de la uniformidad y consiguiente seguridad jurídica es conveniente que se establezcan criterios comunes sobre la materia, a modo de protocolo de actuación al que puedan acudir los operadores jurídicos.

3. Dada la diversidad de fuentes sobre guarda y custodia, y teniendo en cuenta la distribución de competencias entre Estado y Comuni-

${ }^{58}$ SSTS de 9 de marzo de 2012 y 12 de diciembre de 2013.

${ }^{59}$ SSTS de 7 de julio de 2011, 19 de abril de 2012 y 29 de abril de 2013.

(C) UNED. Revista de Derecho UNED, núm. 14, 2014 
dades Autónomas, la uniformidad únicamente puede lograrse mediante la jurisprudencia emanada del TS en cumplimiento de las funciones nomofiláctica y uniformadora que tradicionalmente tiene atribuidas.

4. En materia de guarda y custodia ha de prevalecer el supremo interés del menor sobre cualquier otra consideración. Para su determinación hay que escudriñar las circunstancias casuísticamente.

5. La transcendental STS 29 abril 2013 (EDJ 2013/58481) establece como doctrina jurisprudencial que la guarda y custodia compartida ha de considerarse como el régimen normal y más conveniente para el menor.

6. En la actualidad existe un abundante cuerpo de doctrina jurisprudencial emanado de las sentencias contestes del TS al pronunciarse sobre numerosas cuestiones concretas relacionadas con la guarda y custodia compartida. Jurisprudencia que, como complemento del ordenamiento jurídico que es, debe ser aplicada por los órganos judiciales, y en cualquier caso es apta para fundamentar el recurso de casación por interés casacional.

7. El cauce para el acceso a la casación de los pronunciamientos sobre guarda y custodia es el previsto en el art 477.2.3 de la LEC, es decir, por interés casacional. También cabe impugnar las infracciones procesales que puedan producirse cuando concurran los requisitos para el recurso extraordinario por infracción procesal.

8. La reforma en curso no aporta modificaciones sustanciales al actual sistema de guarda y custodia, haciendo oídos sordos a las demandas de la sociedad actual, a las más recientes tendencias jurisprudenciales y a las novedades legislativas de ámbito autonómico. No obstante, el Anteproyecto amplía el abanico de posibilidades y abre las puertas a la custodia compartida a través de su reconocimiento expreso, lo que puede generar confianza e incrementar las peticiones. En todo caso, la nueva regulación cerrará las puertas a futuras decisiones judiciales denegatorias de la guarda y custodia compartida por el mero hecho de que no estar contemplada en la legislación vigente.

9. La nueva redacción ni tan siquiera establece la guarda y custodia compartida como la opción más deseable en defecto de acuerdo ${ }^{60}$,

${ }^{60}$ A pesar de que varias normas autonómicas sí lo hacen, lo que provoca además una desigualdad carente de fundamento. Así por ejemplo el Código de Derecho Foral de Aragón, artículo 80.2: «El Juez adoptará de forma preferente la custodia compartida en interés de los hijos menores,...». Y también el Código Civil de Cataluña, Libro Segundo, artículo 233.10: 2 . "La autoridad judicial, si no existe acuerdo o si este no se ha aprobado, debe determinar la forma de ejercer la guarda, ateniéndose 
a pesar de que la realidad social actual parece propugnar como más conveniente que se convierta en la regla o modelo general, sin perjuicio de que se pueda acreditar la conveniencia de atribuir la guarda y custodia a uno solo de los progenitores en el caso concreto.

10. La doctrina jurisprudencial sobre guarda y custodia compartida que resulta de la STS 257/2013, de 19 de abril, no perderá su vigencia aún cuando se apruebe el Anteproyecto en trámite sin modificaciones, puesto que el fundamento de la citada resolución judicial no resulta contrario a la nueva redacción. Esta es, por tanto, la tabla de naufrago a la que la sociedad española debe agarrarse para conseguir flexibilizar el régimen de guarda y custodia tradicional.

\section{BIBLIOGRAFÍA}

ALBALADEJO, M.: Derecho Civil. (Introducción y Parte General). Volumen Primero. Bosch, Barcelona, 1991.

ÁLVAREZ LÓPEZ, C.: «Más sobre la custodia compartida». El Derecho Editores. Base de Datos de Bibliografía.

BONET NAVARRO, A.: «Los recursos en el proceso civil». La Ley, Madrid, 2000.

CORDÓN MORENO F. y OTROS: Comentarios a la Lec. Aranzadi, Navarra, 2001.

CORTÉS DOMÍNGUEZ, V., GIMENO SENDRA, V, MORENO CATENA, V.: Introducción al derecho procesal y derecho procesal civil (Parte general y especial). Colex, Madrid, 2000.

CRESPO GARRIDO, M. ${ }^{\mathrm{a}}$ y MORETÓN SANZ, M. ${ }^{\mathrm{a}}$ F.: Conciliación de trabajo y familialas claves del éxito: eficiencia empresarial e implicación masculina. Editorial Colex, Madrid, 2010.

DE LOS RÍOS GONZÁLEZ, M.: «Cambio de guarda y custodia. El síndrome de alienación parental. Aspectos prácticos». Revista de

al carácter conjunto de las responsabilidades parentales, de acuerdo con el art. 2338.1. Sin embargo, la autoridad judicial puede disponer que la guarda se ejerza de modo individual si conviene más al interés del hijo» Por último, la Ley Valenciana va incluso más allá, estableciendo como regla general la guarda compartida aún cuando las relaciones entre los progenitores no sean buenas. Dice así su artículo 5. 2. «Como regla general, atribuirá a ambos progenitores, de manera compartida, el régimen de convivencia con los hijos e hijas menores de edad, sin que sea obstáculo para ello la oposición de uno de los progenitores o las malas relaciones entre ellos». 
Derecho de Familia: Doctrina, jurisprudencia, legislación. págs. 310 y sigs.

GONZÁLEZ DEL POZO, J. P.: «Comentarios parciales al anteproyecto de ley sobre el ejercicio de la corresponsabilidad parental en caso de separación, nulidad y divorcio». El Derecho Editores. Revista de Derecho de Familia El Derecho, n. ${ }^{\circ} 13$.

LASARTE ÁlVAREZ, C.: Principios de Derecho civil. Tomo 6. Derecho de Familia. Marcial Pons, Madrid, 2013, 12. ${ }^{\mathrm{a}}$ ed.

LORCA NAVARRETE, A. M.: Tratado de Derecho Procesal Civil. (Parte general. El nuevo proceso civil). Dykinson, Madrid, 2000.

MAGRO SERVET, V.: «Custodia compartida. Respuesta de los Tribunales», El Derecho Editores. Revista de Jurisprudencia El Derecho, n. ${ }^{\circ} 2$, pág. 5 .

MORENO VELASCO, V.: «Acercamiento a las medidas judiciales ante el síndrome de alienación parental». El Derecho Editores. Diario de Jurisprudencia El Derecho, n. ${ }^{\circ} 2482$, pág. 1.

MONTERO AROCA, J., FLORS MATÍES, J. y ARENAS GARCÍA, R.: Separación y divorcio tras la Ley 15/2005. Tirant lo Blanch, Valencia 2006.

NIEVA FENOLL, J.: El Recurso de Casación ante el Tribunal de Justicia de las Comunidades Europeas. Bosch, Barcelona, 1998.

PÉREZ VEGA, A.: «La guarda y custodia de los hijos sometidos a patria potestad y la violencia de género». El Derecho Editores. Diario de Jurisprudencia El Derecho, n. ${ }^{\circ} 2206$, pág. 1.

PRIETO FERNÁNDEZ-LAYOS, J. M.: «Posibilidad de fijar un sistema predeterminado de distribución de estancias en caso de custodia compartida». El Derecho Editores. Boletín de Derecho de Familia, n. ${ }^{\circ} 110$.

POUS DE LA FLOR, M. ${ }^{\text {a }}$ P.: «Igualdad conyugal y custodia compartida en la Ley 15/2005, de 8 de julio», Libro-Homenaje al profesor Manuel Amorós Guardiola, Vol. 1, 2006, págs. 1743-1766.

SILGUERO ESTAGNAN, J.: El control de los hechos por el Tribunal Supremo. Dykinson, Madrid, 1997.

TAMAYO HAYA, S. «El ejercicio de la patria potestad y la guarda y custodia en la reforma del derecho civil en materia matrimonial», Texto de la ponencia expuesta en el Congreso Internacional de Derecho de Familia. Año 2005. Cd. 
VÁZQUEZ IRUZUBIETA, C.: Comentarios a la nueva LEC. Doctrina y jurisprudencia ley 1/2000. Editorial Dijusa, Madrid, 2000.

VII. ÍNDICE DE RESOLUCIONES JUDICIALES

\section{Tribunal Constitucional}

STC 185/2012, de 17 de octubre

\section{Tribunal Supremo}

STS de 21/07/2011 (RC 338/2009)

STS de 22/07/2011 (RC 813/2009)

STS de 03/10/2011 (RC 1965/2009)

STS de 10/01/2012 (RC 1784/2009)

STS de 09/03/2012 (RC 113/2010)

STS de 29/04/2013 (RC 2525/2011)

STS de 07/06/2013 (RC 1128/2012)

STS de 19/07/2013 (RC 2964/2012)

STS de 19/11/2013 (RC 2637/2012)

STS de 29/11/2013 (RC 494/2012)

STS de 12/12/2013 (RC 774/2012)

STS de 17/12/2013 (RC 2645/2012) 
